\title{
Where Do We Go From Here?
}

\author{
Gordon E. Pike, MRS President
}

In another article in this issue of the BULLETIN, outgoing MRS President Elton Kaufmann has described the ferment of activities of the Materials Research Society in 1985 . It should be clear from this that the Society continues not only to expand, but also to encompass new activities which are beneficial to its members and to the materials research community at large. Society efforts this coming year will maintain this trend, but not as a blind goal. Growth for its own sake is not desirable for MRS since it may misdirect our valuable human resources away from the central purposes of the Society. MRS was established to foster interaction between scientists of many disciplines working on common materials problems, to hold interdisciplinary meetings for such people, and to disseminate related information. The focus of the 1986 officers and committees will be directed toward actively implementing these goals while concurrently stabilizing the organizational structure which makes successful implementation possible.

Probably the most visible committee of MRS, at least in terms of its projects, is the Program Committee. This committee, chaired by Rod Quinn in 1986, is charged with identifying the new, emerging materials research areas which we should be covering in our Spring and Fall technical meetings. The responsibility for this lies principally with the future meeting chairs who are all members of this committee. Topic selection for a given meeting proceeds more or less independently, but with cooperative recognition of the plans for other meetings. For that reason each triad of meeting chairs has been selected with deliberate attention to balance their disciplinary background, materials interest, and institutional setting. An examination of past and future symposium topics shows that this strategy has been successful for realizing one of the main MRS purposes. However, the job of the meeting chairs does not end there. They are also responsible for orchestrating their entire meeting. While this gives them substantial creative freedom, it also imposes obligations of a nontechnical nature. A continuing major goal for this year is to increase the nontechnical support to the meeting and symposium chairs through MRS Headquarters.

The dissemination of information useful to scientists performing interdisciplinary materials research is a duty assigned primarily to the Publications Committee. There are currently three robust projects within this committee to provide this dissemination under the overall chair-

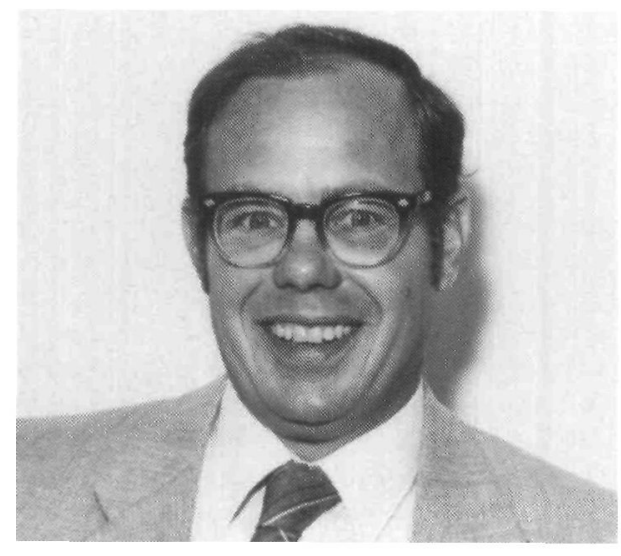

manship of David Campbell. The MRS BULLETIN is the Society's organ to provide information of general interest to the materials research community. For the past several years the BULLETIN has been rapidly evolving from the status of a member newsletter toward that of a recognized resource for a broad spectrum of materials scientists. The new chairman of the BULLETIN Editorial Board, Elton Kaufmann, has set a course to make the contents more comprehensive by the inclusion of more international news and invited technical articles and guest editorials. A second component of the Publications Committee is the production of the MRS Proceedings Series. This widely recognized series is the complete and faithful record of results reported in the various symposia at the MRS meetings. As such it provides "snapshots" in time of the progress of research in many advancing areas. Increased placement of the proceedings into libraries around the world is a principal goal for 1986.

The third and newest project under the wings of this committee is Journal of Materials Research. Under the direction of Editor-in-Chief Charles B. Duke, and its international board of Principal Editors, it may appear to be an independent entity. However, as the official archival journal of the Society, it is subject to our care and nurture. Our intent is to make this journal the premier publication for the disclosure of forefront materials research in widespread topical areas. Journal of Materials Research has been designed to record original research. This makes JMR a natural extension of our meetings, and members of MRS can anticipate the high quality and rich coverage of its contents. However, a tremendous effort is still required to inform the "outside world" of this new initiative. This is the most challenging goal for the publications Committee, and the rest of the Society, for this year.

\section{President Pike outlines goals and identifies MRS leaders who will pursue them.}

In any learned society the issue of education arises in many forms, and so it is within MRS. For the last few years educational projects of the Society have been sub-divided, somewhat arbitrarily, within the Education Committee into those concerned with students still in school and those affecting practitioners. While this separation is neither orthogonal nor unique, it has served a purpose. The co-chair for student issues is Carolyn Aita. The main concentration of her sub-committee will be on the establishment of an aid to MRS student chapters. Through these chapters the Society hopes to expose students to the benefits of interdisciplinary research. This committee will administer the Travel Grant Program to bring students to MRS meetings and the newly instituted Distinguished Lecturer Program to bring speakers to chapter meetings. The issue of MRS contributions to university curricula in materials science will also be addressed.

The co-chair for continuing education in materials research is L. Ralph Dawson, whose pincipal goal for this year is continued development of the MRS Short Course Program. This program provides intense instruction in new technologies which, to a large extent, reflect the forefront topical coverage of our meetings.

The growth of the Materials Research Society has attracted the attention of many national and international groups which have approached MRS with a variety of requests. To formulate sensible and meaningful responses to these groups, and to initiate projects having an impact beyond the Society membership, an External Affairs Committee was formed by MRS Council one year ago. If the first year of operation is a good indicator, this committee chaired in 1986 by Fred Young, Jr. will have a substantial number of unforeseen projects to consider. These, of course, will be in addition to the existing goals of examining national Continued 
issues of concern to the materials research community, promoting cooperation with European-MRS, and offering organizational assistance to materials research groups in Asia.

All of the above activites are fairly visible to members and nonmembers alike. Less visible-but no less important-is the foundation or infrastructure of the Society which makes this all possible. MRS Headquarters, founded a little more than two years ago, is now an indispensable support group. In the coming years, Headquarters will be asked to shoulder more of the nontechnical chores of operating the Society, with the assistance of a number of important committees. The Finance Committee chaired by Susan Kelso is responsible for the financial health of MRS. It will be examining its detailed budgets and making recommendations concerning fund-raising activities. The Corporate Participation Committee is chaired this year by Julia Phillips and is entrusted with the job of involving corporations in support of MRS in general and the individual symposia at our meetings in particular. Our membership base is an obvious resource, and the Membership Committee under Rod Ewing has the task of adding to this base. The organization of Local Sections of MRS is one of the goals in this committee. Finally, the Public Relations and Publicity Committee chaired by Russ Pinizzot to is responsible for describing all of the Society's activities to non members, both technical and laymen.

I have tried to describe briefly the ideological and operational structure of the Materials Research Society, and indicate some of the major goals for this year. As with past goals, these will be met through the efforts of talented and dedicated workers. I invite each reader to join this extraordinary group of individuals by volunteering to work on some aspect of MRS activities in which they have a personal interest.

MRIS

\section{SPECIAL OFFER FOR MRS MEMBERS}

\section{SAVE $\$ 50$ \\ Pearson's Handbook of Crystallographic Data for Intermediate Phases

\author{
By Pierre Villars and L. D. Calvert
} \\ Published by American Society for Metals}

MRS members may purchase the 1985 edition of this important handbook at special MRS member prices.

To take advantage of this offer, complete this form and return it with payment to the Materials Research Society.

$$
\text { Regular Price/Set } \$ 420 \quad \text { MRS Member Price/Set } \$ 370
$$

\section{PEARSON'S HANDBOOK OF CRYSTALLOGRAPHIC DATA FOR INTERMETALLIC PHASES (1985)}

I am a member of the Materials Research Society and would like to take advantage of this special offer on the Pearson's Handbook.

No. of Sets

Price Total Enclosed

Prepayment required. Make check payable to Materials Research Society.

Name

Institution

Address

City State Zip/Postal Code

Telephone

RETURN TO: Materials Research Society, 9800 McKnight Road, Suite 327, Pittsburgh, PA 15237; telephone (412) 367-3012 
$4=$

WIERESTED W SIMPLIFED THERTMAL ANALYSSS SET-UP?
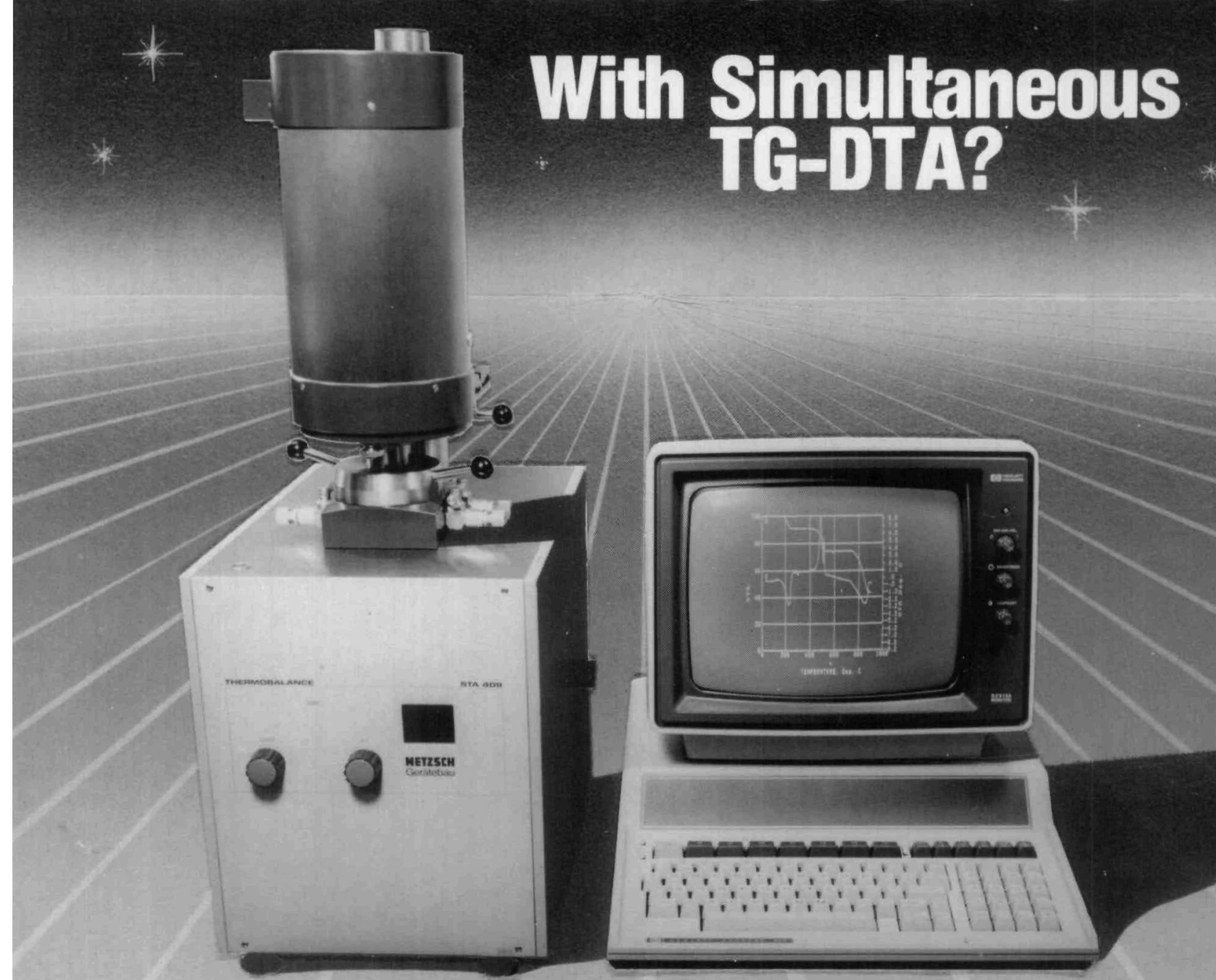

\section{The Netzsch STA 409}

1. Weigh sample. Place in furnace.

2. Set system balance to zero. (2 simple controls)

3. Program furnace microprocessor (Less than 60 seconds)

4. Press start. TG and DTA readouts are automatic!
- Temperature range: $-160^{\circ} \mathrm{C}$ to $+1700^{\circ} \mathrm{C}$

- Vacuum capability to $5 \times 10^{-4}$ Torr.

- Inert gas atmosphere

- Corrosive gas atmosphere

- Steam atmosphere to $+1700^{\circ} \mathrm{C}$

- Thermal analysis software

- Mass spectometer interfacing available

For more information on the STA 409 or any other Netzsch Thermal Analysis Instruments, please call or write today.

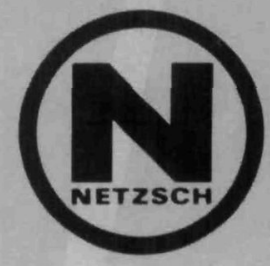

NETZSCH INCORPORATED

Thermal Analysis Division

119 Pickering Way

Exton, PA 19341-1393

TEL: (215) 363-8010 - TWX: 510-663-9340

CABLE: NETZSCHINC 